\title{
Atrial Lead
}

National Cancer Institute

\section{Source}

National Cancer Institute. Atrial Lead. NCI Thesaurus. Code C80462.

The wire which connects a pacemaker or defibrillator to the atrial tissue. 